\title{
Caucasus Mathematical Olympiad
}

Daud Mamiy (Adyghe State University, Maykop, Russia)

On 13-18 March 2017, Maykop (Republic of Adygea, Russian Federation) hosted the Second Caucasus Mathematical Olympiad (an International Olympiad for secondary school students).

The first Olympiad was held in the 2015-16 academic year at the "Sirius" Educational Centre (Sochi, Russia), with students participating from 15 regions of Southern Russia.

It was only in 2017 that the Caucasus Mathematical Olympiad accomplished its original intention, bringing together school students and representatives of various regions of Southern Russia and becoming international. From 15 southern regions of Russia and countries of the South Caucasus: Armenia, Abkhazia, and South Ossetia, 110 students took part in the Olympiad.

The creators of the Olympiad set the humanistic objective of contributing to the formation of a unified cultural and educational space, which would unite regions of Southern Russia, the Caucasus and countries from the Black Sea region, and strengthening ties between school students keen on mathematics from these regions. One of the main goals of the Olympiad is to prepare students for the final stages of the National Olympiads in the participating countries.

The Coordination Council oversaw the development of the Olympiad and its preparation. The Coordination Council of the Olympiad included Daud Mamiy, initiator of the Olympiad, Nazar Agahanov, member of the Coordination Council of the International Mathematical Olympiad, and Nikolai Andreev, Head of the Laboratory of Popularization and Promotion of Mathematics of the Steklov Mathematical Institute of the Russian Academy of Sciences.

In 2017, the members of the central committee of the Russian Mathematical Olympiad responsible for subjectspecific methods of teaching formed the Problem Selection Committee of the Olympiad. Pavel Kozhevnikov served as the Chairman of the Problem Selection Committee. Kozhevnikov himself was a Gold Medallist of the International Mathematical Olympiad in 1992 (currently he is at the Moscow Institute of Physics and Technology, Laboratory of Popularization and Promotion of Mathematics of the Steklov Mathematical Institute of the Russian Academy of Sciences).

The Jury of the Caucasus Mathematical Olympiad consisted of members of the Jury of the Russian Mathematical Olympiad, who were previous winners of Russian and International Olympiads.

The Olympiad was held in two age groups: Junior League for students of Grades 8-9 and Senior League for students of Grades 10-11 (last two years of high school). The Coordination Council invited the winners of the regional and final rounds of the national Mathematical Olympiads of the participating countries to enter the competition. The Olympiad was held over two rounds in which the participants were asked to solve four problems.

The organisers tried to create an atmosphere that realised the intent of the Olympiad; the entire programme aimed to create a friendly and creative atmosphere. The organisers provided consultants who discussed and reviewed the problems of the previous rounds with the delegations from any regions where the level of mathematical training is not high enough.

In the evenings, volunteers from Maykop schools and students of Adyghe State University organised guitar and music concerts. Without doubt, the Olympiad participants and the members of the jury enjoyed the informal gatherings, where they talked about the problems, their preparation for Olympiads and anything else that was of interest.

The programme of the Olympiad was also designed to introduce the guests of Adygea to the local history, culture and traditions. The contestants visited the National Museum of the Republic of Adygea and the Northern Caucasus branch of the State Museum of Oriental Art, travelled to the foothills of the Western Caucasus, attended lectures on the history and culture of a local ethnic group called Circassians and became familiar with Circassian cuisine. Every night, dancers from the Dance Ensemble "Nart" of Adyghe State University taught everybody who was interested how to dance Caucasian dances.

The members of the Coordination Council were very involved during the Olympiad, attending numerous meetings with teachers of mathematics, university students and schoolchildren from almost all districts of the Republic of Adygea. Schoolteachers gathered at roundtables to discuss problems of student training for Olympiads. Teachers also attended lectures on how to engage students in mathematics, while young mathematics enthusiasts had the chance to attend lectures on popular mathematics that were taking place in all districts of the Republic of Adygea for three days.

The Olympiad events were updated on its website (http://cmo.adygmath.ru/en) and on the social network "VKontakte" (https://vk.com/cmo.adygmath). Volunteer students of Adyghe State University formed the press centre for the Olympiad and uploaded more than 1000 photos (http://cmo.adygmath.ru/node/31) of the most interesting moments of the Olympiad, as well as short videos and dozens of posts.

The opening and closing ceremonies of the Olympiad were very impressive and reflected the diversity of the cultures of people living in the Caucasus. It is not a coincidence that the closing ceremony ended with a song "Our Caucasus", beautifully performed by the soloists of the Adyghe State University musical theatre "Art Rhyton". The Olympiad closing ceremony was held in the Main Hall of the State Philharmonic of Adygea. 


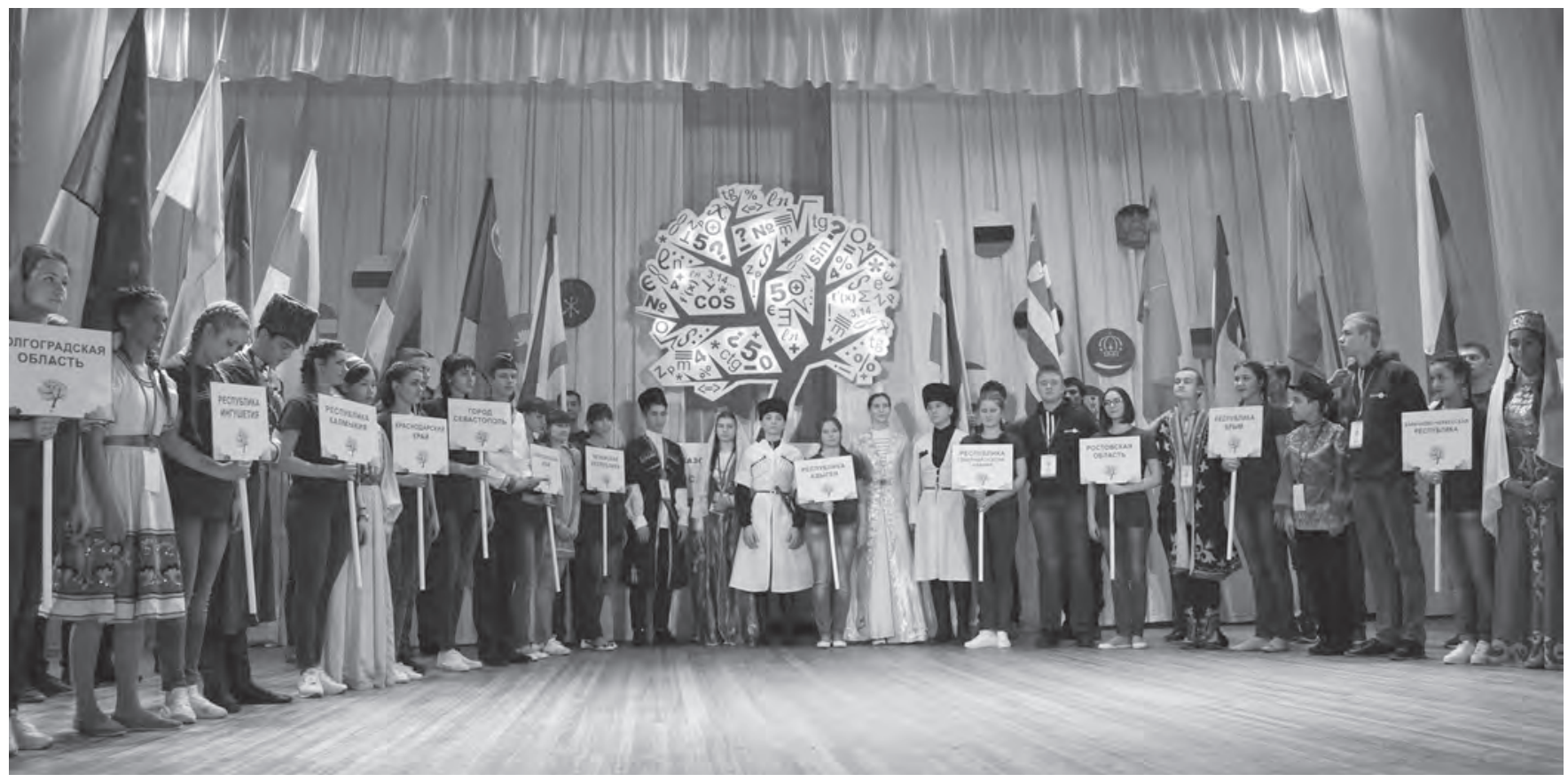

It should be added that the emblem of the Caucasus Mathematical Olympiad is the Caucasian tree of mathematical knowledge, designed by a talented Maykop painter Tatiana Vaganova. At the opening ceremony of the Olympiad, the delegates lit their symbolic signs on the branches of this tree and later, during the closing ceremony, they put the lights out. Most of the audience could not hold back their tears because they had made great friends and did not want to part from each other.

The jury awarded various diplomas and gifts to 72 participants from the regions and participating countries for their achievements. Forty-one of these participants were Olympiad champions and prize winners. The overall winners of the Olympiad were three students from Armenia and six students from regions of Russia (Adygea, Dagestan and the Krasnodar region).

Apart from the diplomas and prizes, each of the winners of the Olympiad received a pendant in the shape of a blade. The pendants were created by the famous Circassian jeweller and gunsmith, Asiya Eutykh, who made them from a unique alloy used by Circassians in ancient times.

Four winners of the Olympiad who succeeded in solving all eight problems got special prizes from Murat Kumpilov, the Head of the Republic of Adygea.

The second and third place winners were participants from the Republic of Armenia and from eight regions of Southern Russia: the Astrakhan region, the Republic of Adygea, the Volgograd region, the Republic of Dagestan, the Rostov region, the Krasnodar region, the Republic of Crimea and the Republic of Kalmykia. All winners received memorable prizes and gifts.

The organisers of this Olympiad were the Ministry of Education and Science of the Republic of Adygea and Adyghe State University. The idea of hosting the Olympiad in Adygea was actively supported by the authorities of the Republic, who helped cover the major cost of the Olympiad. The sponsor of the Olympiad was an ITV company, a Russian market leader in video-editing.

The success of the Olympiad is largely linked to the activity of the Adygea Regional School of Mathematics and Natural Sciences, which has extensive experience in hosting mathematical competitions and conferences at the highest level.

The Caucasus Mathematical Olympiad of 2017 achieved its objectives and goals. Apart from the mathematical contest experience, schoolchildren from different regions of the Caucasus got to know each other and made new friends. The results of the Second Caucasus Mathematical Olympiad highlight the necessity of carrying it forward into subsequent years. To maintain the current format, the Olympiad of 2018 will take place in Adygea again. We hope that the participants from other countries of the Caucasus and the Black Sea region will attend this event in the future. We will be happy to welcome students of Azerbaijan, Bulgaria, Georgia, Romania, Turkey, Ukraine and other countries. The Olympiad is further expected to be held under the direction of the Coordination Council in other countries of the Caucasus, the Black Sea region and Southern Russia.

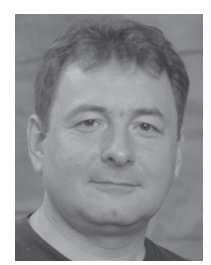

Daud Mamiy(dmami@yandex.ru) is the Initiator of the Caucasus Mathematical Olympiad and Head of its Coordination Council. He received his degree in mathematics at Lomonosov Moscow State University in 1987 and his PhD in mathematics in 1991 also from Lomonosov Moscow State University. Daud Mamiy is the Dean of the Faculty of Mathematics and Computer Science of Adyghe State University. He is the Director of the ASU School for mathematically gifted students. 